ORIGINAL ARTICLE

\title{
Frequency of Depression in patients of Chronic Hepatitis C who had not yet received treatment
}

\author{
ABDULLAHI ADAM ${ }^{1}$, AIJAZ ZEESHAN KHAN CHACHAR ${ }^{2}$, MIQDAD HAIDER ${ }^{3}$, NAZISH YAQOOB ${ }^{4}, \mathrm{MOHSIN} \mathrm{ASIF}^{5}$, \\ MUBBASHIR ALI ${ }^{6}$ \\ ${ }^{1}$ Registrar, Medicine, Department of Medicine, Fatima Memorial Hospital, Shadman, Lahore. \\ ${ }^{2}$ Senior Registrar, Fatima Memorial Hospital College of Medicine \& Dentistry, Lahore. \\ ${ }^{3}$ Post graduate resident, Department of Medicine, Fatima Memorial Hospital, Shadman, Lahore. \\ ${ }^{4}$ Woman Medical Officer, Mian Mir Hospital, Lahore \\ ${ }^{5}$ Registrar, Fatima Memorial Hospital, Lahore \\ ${ }^{6}$ Registrar, Indus Hospital, Lahore \\ Correspondence to Dr. Aijaz Zeeshan Khan Chachar Email: dr_aijaz84@hotmail.com, Cell: 0333-2612096
}

\begin{abstract}
Background: Chronic hepatitis $C$ is a common entity which is frequently associated with depression.

Aim: To determine the frequency of depression in patients of chronic hepatitis $C$ who had not yet received treatment.

Settings: Department of Gastroenterology and Medicine at Fatima Memorial Hospital Lahore, Pakistan.

Study design: Cross sectional Descriptive study

Methods: Total 217 patients were enrolled. Each patient was interviewed and then marked down by the doctor himself. Patient Health Questionnaire (PHQ 9) (annexure 2 attached) was applied to determine the presence of depression. Depression was managed as per hospital protocol. The study was conducted from $10^{\text {th }}$ April, 2018 to $9^{\text {th }}$ October, 2018

Results: In this study mean age was 45 years with standard deviation \pm 11.33 . $62 \%$ patients were male, $38 \%$ patients were female. More over $57 \%$ patients had depression while $43 \%$ patients didn't have depression.

Conclusion: Our study concluded that there was a significant association between depression and chronic hepatitis $C$ patients before they have started their treatment, in tertiary care hospital.

Keywords: Depression, chronic, hepatitis C
\end{abstract}

\section{INTRODUCTION}

Three percent of human population worldwide suffers from Hepatitis C. It can lead to serious complications including liver fibrosis and cirrhosis, and in some cases, hepatocellular carcinoma (HCC) ${ }^{1}$. It is now the leading indication for liver transplantation and will continue to pose a major health and economic burden during the next 10 to 20 years. It affects an estimated 170 million people worldwide and accounts for 366000 deaths annually. ${ }^{2}$ Since Hepatitis C virus (HCV) is a blood borne infection, contact with blood and blood products is the primary route of transmission. However HCV (RNA) ribonucleic acid (RNA) has been recovered from almost all body fluids like saliva, urine, semen and ascitic fluid, they play a little role in the transmission of HCV. In Pakistan major risk factors for the transmission of HCV include intravenous injections after reusing syringes and needles, and sharing of blades at barber shops ${ }^{3}$.

Depression is a type of mood disorder characterized by low mood, anhedonia (lack of pleasure) and anergia (abnormal lack of energy). These should be present for over two weeks. Hepatitis has many associate complications resulting from hepatic insufficiency and portal hypertension hence having an overall negative impact on quality of life of the patients. It may also give rise to nonhepatic complications such as depression, sleep disorders, fatigue, among others ${ }^{4}$. Prevalence of Depression in patients of Hepatitis C is estimated to $59.4 \%$; making it the most common psychiatric symptom in such patients. Quality of life is reduced as a result of mental health issues which eventually affect negatively to the compliance towards the treatment. Depression can diagnosed by ICD10 criteria or the DSM-IV criteria and can be further termed as mild, moderate, severe or severe with psychotic features. Laboratory investigations are not helpful for confirmation of its diagnosis, which is basically made through proper history and physical examination. A large number of international and local studies are available on depression in chronic hepatitis $\mathrm{C}$, but the focus has only been kept on treatment related depression only ${ }^{5}$.

The objective of the study was to determine the frequency of depression in patients of chronic hepatitis C who had not yet received treatment.

\section{PATIENTS \& METHODS}

This cross Sectional descriptive study was conducted in Department of Medicine and Gastroenterology of Fatima memorial Hospital, Lahore during six months after approval from ethical committee. Sample size was 217 keeping expected percentage of depression in patient with chronic hepatitis C $59.4 \%{ }^{5}, 95 \%$ confidence interval, $11 \%$ margin of error. According to $\mathrm{WHO}$ formula for sample size technique used for sampling was consecutive non-probability sampling technique.

Inclusion criteria: All patients of both genders between the age of $18-60$ years having Anti-HCV antibodies positive by enzyme-linked immunosorbent assay (ELISA) for more than 6 months

\section{Exclusion criteria}

- Patients who were on treatment for hepatitis C or had already been treated

- Patients having concomitant chronic hepatitis B 
- Patients having other chronic diseases like diabetes, stroke, etc

Data collection procedure: Prior approval from the hospital ethical committee was taken before commencing the study. All the patients satisfying the inclusion criteria were enrolled through the patient department (OPD) or admitted in wards of gastroenterology and Medicine departments of Fatima memorial Hospital Lahore. A written \& informed consent was taken by us. Proforma and consent form are attached in Annexure-I. Each patient was interviewed and details were noted by us. Patient Health Questionnaire (PHQ-9) was translated into urdu as well (Annexure-2) and was applied to determine the presence of depression. Depression was managed as per hospital protocol and help was also taken by a senior clinical psychiatrist with vast experience in this field in dealing such cases to confirm our findings to avoid any bias.

Statistical analysis: All the data was entered and analyzed in IBM SPSS 23.0. Qualitative variables i.e. age and duration of Hepatitis $C$ were presented in the form of mean and standard deviation SD. Qualitative variables i.e. gender, socio economic status, educational status was presented in frequency and percentages. Data was stratified for gender, age, duration of Hepatitis C, socio economic status, education status. Post stratification chi square test was applied in which $P$ value $\leq 0.05$ was considered as significant.

\section{RESULTS}

Age group distribution showed that $22(10 \%)$ patients were in age ranged $18-30$ years, $39(18 \%)$ patients were in age ranged $31-40$ years, $74(34 \%)$ patients were in age ranged 41-50 years, 82 (38\%) patients were in age ranged 51-60 years. Mean age was 45 years with standard deviation \pm 11.33 . 135(62\%) patients were male, $82(38 \%)$ patients were female.

Duration of HCV among 217 patients was analyzed as $111(51 \%)$ patients had duration of $\mathrm{HCV} \leq 1$ year while $106(49 \%)$ patients had duration of $\mathrm{HCV}>1$ year. Mean duration was 1 year with standard deviation \pm 4.21 (Table 3). As per socioeconomic status, 115(53\%) patients were poor, $76(35 \%)$ patients were middle class, $26(12 \%)$ patients were rich. 110(51\%) patients were illiterate, $85(39 \%)$ patients were matric, $22(10 \%)$ patients were higher. 124(57\%) patients had depression while 93(43\%) patients didn't had depression. Out of these 124, 66 belonged to poor economic status, 43 to middle class and 15 were from rich economic class ( $p$ value 0.91). Stratification of depression with respect to age, gender, duration of Hepatitis $\mathrm{C}$ and education status is given in table $1,2,3$ respectively.

Table1: Stratification of depression w.r.t age distribution. $\quad(n=217)$

\begin{tabular}{|l|c|c|c|c|c|}
\hline Depression & $\mathbf{1 8 - 3 0}$ years & $\mathbf{3 1 - 4 0}$ years & $\mathbf{4 1 - 5 0}$ years & $\mathbf{5 1 - 6 0}$ years & Total \\
\hline Yes & $12(5.5 \%)$ & $22(10.1 \%)$ & $42(19.3 \%)$ & $48(22.1 \%)$ & $124(57.1 \%)$ \\
\hline No & $10(4.6 \%)$ & $17(7.8 \%)$ & $32(14.7 \%)$ & $34(15.6 \%)$ & $93(42.8 \%)$ \\
\hline Total & $22(10.1 \%)$ & $39(17.9 \%)$ & $74(34.1 \%)$ & $82(37.7 \%)$ & $217(100 \%)$ \\
\hline
\end{tabular}

Table 2: Stratification of depression w.r.t gender distribution and duration of HCV $(n=217)$

\begin{tabular}{|c|c|c|c|c|c|c|}
\hline \multirow{2}{*}{ Depression } & \multicolumn{3}{|c|}{ Age } & \multicolumn{3}{|c|}{ Duration of $\mathrm{HCV}$} \\
\hline & Male & Female & Total & $\leq 1$ year & $>1$ year & Total \\
\hline Yes & $77(35.4 \%)$ & $47(21.6 \%)$ & $124(57.1 \%)$ & $63(29.0 \%)$ & $61(28.1 \%)$ & $124(57.1 \%)$ \\
\hline No & $58(26.7 \%)$ & $35(16.1 \%)$ & $93(42.8 \%)$ & $48(22.1 \%)$ & $45(20.7 \%)$ & $93(42.8 \%)$ \\
\hline Total & $135(62.2 \%)$ & $82(37.7 \%)$ & $217(100 \%)$ & $111(51.1 \%)$ & $106(48.8 \%)$ & $217(100 \%)$ \\
\hline
\end{tabular}

Table 3: Stratification of depression w.r.t education level $(n=217)$

\begin{tabular}{|l|c|c|c|c|}
\hline Depression & Illiterate & Matric & Graduates & Total \\
\hline Yes & $63(29.0 \%)$ & $48(22.1 \%)$ & $13(5.9 \%)$ & $124(57.1 \%)$ \\
\hline No & $47(21.6 \%)$ & $37(17.0 \%)$ & $9(4.1 \%)$ & $93(42.8 \%)$ \\
\hline Total & $\mathbf{1 1 0}(50.6 \%)$ & $\mathbf{8 5}(39.1 \%)$ & $\mathbf{2 2}(10.1 \%)$ & $\mathbf{2 1 7}(100 \%)$ \\
\hline
\end{tabular}

\section{DISCUSSION}

Hepatitis $\mathrm{C}$ is a global issue. It is a major reason for both acute and chronic hepatitis. Total global HCV prevalence is estimated at $2.5 \%{ }^{6}$. As per estimates of World Health Organization (WHO), around $3 \%$ of the total population of the world has been infected with this virus while there are over 170 million carriers who can develop advanced liver disease, including cirrhosis or even Hepatocellular Carcinoma?.

The HCV, which is a blood borne virus which can be transmitted through various means, such as transfusion of blood products without proper screening, use of injections without following safe guidelines and poor sterilization of medical equipment. In one study conducted in Peshawar $\mathrm{KPK}$, risk factors distribution among $252 \mathrm{HCV}$ positive patients was: intravenous drug abuse $29 \%$, HCV positive sexual partners $23.01 \%$, blood or blood product transfusion $13.49 \%$, occupational exposure to $\mathrm{HCV} 7.14 \%$ and sporadic transmission $27.38 \%$. Out of the total sample $54.36 \%$ had positive family history of hepatitis $\mathrm{C}^{3}$.

Patients who have chronic Hepatitis $\mathrm{C}$ infections are highly vulnerable to develop liver cancer or cirrhosis. The number of people infected with Hepatitis $C$ virus is increasing dramatically. Its prevalence is more than 200 million worldwide and its yearly incidence is 3-4 million worldwide. $^{8,9}$ In different regions of Pakistan, the prevalence of Hepatitis C has varied from $2.2 \%-13.5 \%$ in last 5 years. Lahore has the highest prevalence which is $13.5 \%$, followed by Jamshoro (9\%) and Mardan $(9 \%)^{3}$.

The mean age in our study was 45 years with standard deviation \pm 11.33 . $62 \%$ patients were male, $38 \%$ patients were female. $57 \%$ of the patients were found to 
have depression. In another study conducted by Memon SA et $\mathrm{al}^{10} 59.4 \%$ of the total population included in the study were depressed. $57.9 \%$ of the sample were males and $42.1 \%$ were females. A positive correlation was found with the duration of the illness and depression. These results are very similar to our study.

In an another study completed by by Abbas SM et al, ${ }^{11}$ depression was found in $29 \%$ of the patients with Hepatitis C and $7 \%$ had severe depression. While comparing age groups and gender, patients less than 30 years and females had higher incidence of depression $(p=$ 0.009). Level of education, occupation, socioeconomic status, duration of illness, treatment of hepatitis $\mathrm{C}$ were other factors which had a correlation with prevalence of depression ${ }^{12}$.

In another study Fareed $\mathrm{G}$ et al had reported that $38 \%$ of the patients, whose mean age was 37.82 years, had depression and $4 \%$ had it in the severe form ${ }^{13}$. These results are quite similar to results of our study. When compared with the general population, these patients have a low quality of life and a higher incidence of mental health disorders. This is also seen in patients of other chronic diseases ${ }^{14,15}$.

Kenny-Walsh, in their study, reported that depression was found in $16 \%$ of Irish women of the sample who had iatrogenic hepatitis $\mathrm{C}$. The total study sample was $376^{16}$. Two other studies, done by Lee et al and Dwight et al, showed similar figures, where the prevalence was reported to be $24 \%$ and $28 \%$ respectively where depression was identified via a structured interview done by the psychiatrists $^{17}$.

There is a significant association of Depression in patients infected with $\mathrm{HCV}$. The prevalence ranges from $25 \%$ to $50 \%$. In our study, the prevalence was found to be $59.4 \%$ which is substantial however it is similar to the figures reported by several international studies ${ }^{18}$. An important factor found to be related with higher prevalence was the Gender. In several studies carried out in our country, the prevalence of depression was sometimes twice in women when compared to men. However in our study, no significant difference was noted with respect to gender.

\section{CONCLUSION}

Our study concluded that among chronic hepatitis C patients, $57 \%$ had previously undiagnosed depression. Health care practitioners must keep this aspect in mind while treating such patients, as timely diagnosis and management can avoid many complications and improve quality of life.

Limitations: Our study was single centre with relatively smaller sample size, so results cannot be generalized to whole population.

Recommendations: Hepatitis C causing depression is a disease with high rates of cure but if undiagnosed or untreated patients can greatly affect the quality of life so further multicentre studies with larger sample size are still required. It is the need of the day to create awareness among general population and for general practioners through electronic media, print media and arranging seminars and symposia about the disease and its early diagnosis and so as to prevent the complications related with this disease and by doing so reducing the misery and improving the quality of life.

Contribution: AA: Study Design, Data analysis \& Data Interpretation, Article writing, Review of Literature, Drafting article, AZKC: Conception of the study, Data collection, Review of literature, Review of manuscript, Development of Research Methodology Design, Study Design, Data analysis \& Data Interpretation, Article writing, Review of Literature, Drafting article, final approval of manuscript, MH: Study Design, Data analysis \& Data Interpretation, Article writing, Review of Literature, Drafting article, NY: Data Interpretation, Article writing, Review of Literature, MA: Drafting article, Review of Literature

\section{REFERENCES}

1. Sikorska K, Romanowski T, Stalke P, IzyckaSwieszewska E, PiotrBielawski K. Association of Hepcidin mRNA Expression With Hepatocyte Iron Accumulation and Effects of Antiviral Therapy in Chronic Hepatitis C Infection. Hepatitis Monthly. 2014;14(10).

2. Youssef N, El Kassas M, Farag A, Shepherd A. Healthrelated quality of Life in patients with chronic hepatitis $C$ receiving Sofosbuvir-based treatment, with and without Interferon: a prospective observational study in Egypt. BMC Gastroenterology. 2017;17(1).

3. Rehman N, Orakzai MB, Hayat A, Azam S, Ahmad B, Khan I, Zeb Z. Prevalence of Hepatitis $C$ virus and its risk factors in blood donors in district Peshawar. Pakistan journal of pharmaceutical sciences. 2018 Jan 1;31(1):83-7.

4. Younossi ZM, Stepanova M, Nader F, Lam B, Hunt S. The patient's journey with chronic hepatitis $C$ from interferon plus ribavirin to interferon-and ribavirin-free regimens: a study of health-related quality of life. Alimentary pharmacology \& therapeutics. 2015 Aug 1;42(3):286-95.

5. Hayes JF, Miles J, Walters K, King M, Osborn DP. A systematic review and meta-analysis of premature mortality in bipolar affective disorder. Acta Psychiatr Scand. 2015 Jun $1 ; 131(6): 417-25$

6. Abbas SM, Salama HM, Nour-Eldein H. Depression among adults with chronic hepatitis $\mathrm{C}$ on antiviral treatment in PortSaid, Egypt. Journal of Public Health 2018:1-8

7. Fareed G, Hussain A, Akhtar M, Hayee A, Hussain A, Malik A Incidence of Depression in cases of Chronic Hepatitis C without Interferon therapy. P J M H S 2014;8: 112-14

8. Fortier $E$, Alavi $M$, Bruneau $J$, Micallef $M$, Perram J, Sockalingam S, Dunlop AJ, Balcomb AC, Day CA, Treloar C, Bath N. Depression, anxiety, and stress among people with chronic hepatitis $C$ virus infection and a history of injecting drug use in New South Wales, Australia. Journal of addiction medicine. 2017 Jan 1;11(1):10-8.

9. Felger JC, Haroon E, Woolwine BJ, Raison CL, Miller AH. Interferon-alpha-induced inflammation is associated with reduced glucocorticoid negative feedback sensitivity and depression in patients with hepatitis C virus. Physiology \& behavior. 2016 Nov 1;166:14-21.

10. Machado MO, Oriolo G, Bortolato B, Köhler CA, Maes M, Solmi M, Grande I, Martin-Santos R, Vieta E, Carvalho AF. Biological mechanisms of depression following treatment with interferon for chronic hepatitis C: a critical systematic review. Journal of affective disorders. 2017 Feb 1;209:235-45.

11. Adinolfi LE, Nevola R, Rinaldi L, Romano C, Giordano M. Chronic hepatitis $C$ virus infection and depression. Clinics in liver disease. 2017 Aug 1;21(3):517-34.

12. Conversano C, Carmassi C, Carlini M, Casu G, Gremigni P, Dell'Osso L. Interferon a therapy in patients with chronic 
hepatitis C infection: quality of life and depression. Hematology reports. 2015 Feb 24;7(1).

13. Brunton G, Caird J, Sutcliffe K, Rees R, Stokes G, Oliver S, Stansfield C, Llewellyn A, Simmonds M, Thomas J. Depression, anxiety, pain and quality of life in people living with chronic hepatitis C: a systematic review and metaanalysis. London: EPPI-Centre, Social Science Research Unit, UCL Institute of Education, University College London. 2015 Jan.

14. Murri MB, Cecere AC, Masotti M, Sammito G, la Marca A, Torres GV, Bonfitto I, Cuozzo E, Rossi L, Serviddio G, Villani $R$. Biopsychosocial predictors of interferon-related depression in patients with Hepatitis C. Asian journal of psychiatry. 2017 Apr 1;26:24-8

15. Boscarino JA, Lu M, Moorman AC, Gordon SC, Rupp LB, Spradling PR, Teshale EH, Schmidt MA, Vijayadeva V, Holmberg SD, Chronic Hepatitis Cohort Study (CHeCS)
Investigators. Predictors of poor mental and physical health status among patients with chronic hepatitis $\mathrm{C}$ infection: the Chronic Hepatitis Cohort Study (CHeCS). Hepatology. 2015 Mar;61(3):802-11.

16. Hoyo-Becerra C, Liu Z, Yao J, Kaltwasser B, Gerken G, Hermann DM, Schlaak JF. Rapid regulation of depressionassociated genes in a new mouse model mimicking interferon- $\alpha$-related depression in hepatitis $C$ virus infection. Molecular neurobiology. 2015 Aug 1;52(1):318-29.

17. Ramirez FE, Nedley N, Chon JW. Hepatitis C depression severity decreases after an 8-week educational program. HPB. 2019 Mar 1;21:S160-1.

18. Lucaciu LA, Dumitrascu DL. Depression and suicide ideation in chronic hepatitis $C$ patients untreated and treated with interferon: prevalence, prevention, and treatment. Annals of gastroenterology: quarterly publication of the Hellenic Society of Gastroenterology. 2015 Oct;28(4):440. 